\title{
THE EFFECT OF COVID-19 PHOBIA ON THE SATISFACTION WITH LIFE AND FAMILY SENSE OF BELONGING LEVELS OF MIDWIFERY STUDENTS
}

\section{Sumeyye ALTIPARMAK¹, Ayşe Nur YILMAZ², Yesim AKSOY DERYA ${ }^{3}$}

\author{
${ }^{1}$ Department of Midwifery, Faculty of Health Sciences, Inonu University, Malatya, TURKEY \\ 2 Department of Midwifery, Faculty of Health Sciences, Firat University, Elazıg, TURKEY \\ ${ }^{3}$ Department of Midwifery, Faculty of Health Sciences, Inonu University, Malatya, TURKEY
}

\author{
Address for Correspondence: Associate Professor, Yesim AKSOY DERYA, E-mail: yesim.aksoy@inonu.edu.tr \\ Received: 27.03.2021; Accepted: 20.08.2021; Available Online Date: 20.09.2021 \\ (C) Copyright 2021 by Dokuz Eylül University, Institute of Health Sciences - Available online at https://dergipark.org.tr/en/pub/jbachs
}

Cite this article as: Altiparmak S, Yilmaz AN, Aksoy Derya Y. The Effect Of Covid-19 Phobia on the Satisfaction with Life and Family Sense of Belonging Levels of Midwifery Students. J Basic Clin Health Sci 2021; 3: 66- 75.

\begin{abstract}
Purpose: This research was conducted with the purpose of determining the impact of COVID-19 phobia on the satisfaction with life and family sense of belonging levels of midwifery students.

Methods: Sample of this cross-sectional research consisted of 484 students studying at Midwifery Departments of two universities located in the eastern of Turkey. The data was collected with Personal Information Form, Satisfaction with Life Scale, Family Sense of Belonging Scale and Coronavirus 19 Phobia Scale. Average, standard deviation, percentage distribution and Pearson Correlation Analysis were used in the statistical assessment.

Results: The average score that midwifery students get from Satisfaction with Life Scale was found as $13.54 \pm 4.37$, their average score from Family Sense of Belonging Scale was found as $64.59 \pm 13.29$ and average score from Coronavirus 19 Phobia Scale was found as $50.02 \pm 17.36$. It was determined that Family Sense of Belonging Scale total and all sub-dimension average scores increased significantly as the Coronavirus 19 Phobia Scale "Psychological Phobia" sub-dimension average score increases $(p<0.05)$. In addition, it was determined that Family Sense of Belonging Scale "Family Sense of Belonging" subdimension average score increased significantly as the Coronavirus 19 Phobia Scale "Social Phobia" subdimension average score increases $(p<0.05)$. However, it was determined that Satisfaction with Life decreased significantly as Coronavirus 19 Phobia Scale "Psychosomatic Phobia" and "Economic Phobia" sub-dimension average scores increase $(p<0.05)$.

Conclusions: It was determined that midwifery students have moderate level of COVID-19 phobia and psychological and social phobia levels regarding COVID-19 increase family sense of belonging, but psychosomatic and economic phobia levels decrease satisfaction with life.
\end{abstract}

Keywords: COVID-19 phobia, family belonging, midwifery students, satisfaction with life.

\section{INTRODUCTION}

Coronavirus disease (COVID-19) has occurred for the first time at the end of 2019 in Wuhan City of China. This viral disease with a high rate of contagiousness has turned quickly into a pandemic that affects the entire world. With global development of this pandemic, accompanying psychological problems increase public health burden (1-3). Since 
the first COVID-19 case has been verified, Turkey has tried to take necessary measures by closing down places where people gather in crowds such as schools, shopping centres, gyms to stop the spreading of Covid-19 pandemic just like all countries fighting with this virus (4).

Since death toll increases and virus cannot be taken under control completely, people have been going through various psychological challenges such as fear, panic or phobia. In the literature, it has been reported that similar epidemics such as H1N1, SARS, MERS, Ebola and Zika have had serious adverse effects previously and caused psychological disorders such as fear and anxiety $(2,5)$. Similarly, being exposed to COVID-19 frequently on the printed, visual and social media increases people's anxiety and fear levels (2). In literature review, it was determined that there is an increase in the occurrence of negative emotions such as anxiety, depression, anger and fear and there is a higher susceptibility to social risks together with the epidemic in studies conducted for determining the COVID-19 pandemic's impact on people. Furthermore, there has been a decrease in satisfaction with life with the impact of such negative emotions (6).

Satisfaction with life is one of the most important factors that people should have in order that they are happy and their life has a meaning (7). The satisfaction with life that people experience is affected by the satisfaction they get from their family relationships. In addition, as the satisfaction that individuals get within the family increases, they are more likely to experience positive emotions. Therefore, the emotional atmosphere within the family affects individual's development, emotions and thoughts as well as behaviours towards his/her environment (8). With the connection and sense of belonging between family members, individuals gain resilience against many problems and the ability to fight against problems (9). The most important problem that should be fought in today's world is the pandemic and it is possible that family relations and sense of belonging are affected as well in this process. It is thought that social and even psychological isolation was formed with people staying at home during the pandemic and this isolation would cause withdrawal, distancing, alienation and therefore discussions among individuals (10). With the impact of problems especially such as raising voices, domestic discussions and incidents leading up to domestic violence, a crisis environment would occur within the family (10-12).

Even under normal circumstances, high levels of psychological distress occur in university students. As a result of physical distancing measures implemented due to COVID-19 pandemic, students face psychological problems due to giving up their daily routines, decreasing motivation and increasing pressure towards independent learning. For that reason, together with increasing environmental stress factors, COVID-19 pandemic creates a unique burden on students that constitute a population with high stress levels and low potential of relying on coping strategies (1). This may increase anxiety and concerns of students regarding getting the disease and affect their satisfaction with life and family sense of belonging levels negatively. In the light of this information, the impact of COVID-19 phobia on satisfaction with life and family sense of belonging levels of midwifery students arouses curiosity. This study aims to investigate the effect of COVID-19 phobia on satisfaction with life and family sense of belonging levels in midwifery students.

\section{MATERIAL AND METHODS}

This research in cross-sectional design was conducted with female students studying at midwifery departments of two universities located in the eastern of Turkey between December 2020 - January 2021. There are 635 students in Midwifery Departments of those two universities (University A: 287 and University B: 348) in total. In the study, sample calculation was not made and it was aimed to reach all students. 484 volunteering students who agreed to participate in the study constituted the sample.

\section{Data Collection Tools}

The data was collected using Personal Information Form, Coronavirus 19 Phobia (C19P-SE) Scale, Satisfaction with Life Scale (SLS) and Family Sense of Belonging Scale (FSBS).

\section{Personal Information Form}

This form prepared by the researchers in accordance with literature information, consists of 11 questions regarding descriptive properties of the students included in the research (age, class, family type, relationship status, parents' education level and employment status, etc.) $(2,3,7,9)$. 


\section{Coronavirus 19 Phobia (CP19-SE) Scale}

Developed by Arpacı et al., Coronavirus 19 Phobia (C19P-SE) Scale consists of 20 questions in total (2). Items of this scale provides support for measuring the phobia which might develop against coronavirus among various age groups. The scale is in Likert type and all items are rated between "strongly disagree (1)" and "strongly agree (5)". The scores obtained from the scale may vary between 20 and 100 . The scale has four sub-dimensions; psychological " $1,5,9$, 13, 17, 20", psychosomatic " $2,6,10,14,18$ ", economic " $4,8,12,16$ " and social " $3,7,11,15,19$ ". While sub-dimension scores are obtained by summing up the scores of the answers given to the items in that sub-dimension; total C19P-SE score is obtained by summing up the scores of all subdimensions and it varies between 20 and 100 . Higher scores indicate high score in sub-dimensions and overall corona phobia. Cronbach's Alpha internal consistency coefficient of the scale is determined as 0.92 (2). In this study, Cronbach's Alpha internal consistency coefficient of the scale was found as 0.94 .

\section{The Satisfaction with Life Scale (SLS)}

Satisfaction with Life Scale was developed by Diener et al. and its validity and reliability were made by Daglı and Baysal in Turkey $(7,13)$. Consisting of 5 items in total, the scale is in Likert type and each item is rated between 1-5 $(1=$ Strongly Disagree; $5=$ Strongly Agree). Total score of the scale varies between 5 and 25. Higher score means higher satisfaction with life. Cronbach's Alpha internal consistency coefficient of the scale was determined as 0,88 and test-retest reliability was determined as 0.97 (7). In this study, Cronbach's Alpha internal consistency coefficient of the scale was found as 0.88 .

\section{Family Sense of Belonging Scale (FSBS)}

Family Sense of Belonging Scale is a measurement instrument developed by Mavili, Kesen and Dasbas (2014) with the purpose of measuring individuals' sense of belonging to their families (9). It is a 5-point Likert style scale rated with answers between (1) strongly disagree and (5) strongly agree and it consists of 17 items. Items 5, 7, 9 and 12 are negative items and they are calculated reversely. After reversion is completed; while sum of items $1,3,4,6$, 7, 10, 11, 12, 13, 14, 15, 17 measures "Sense of SelfBelonging Sub-dimension”, sum of items 2, 5, 8, 9, 16 measures "Family Sense of Belonging Subdimension". Sum of the two gives "family sense of belonging total score". In the scale in which a total score can be obtained between 17 and 85 , family sense of belonging increases as the total score increases. Cronbach's Alpha internal consistency coefficient of the scale was calculated as 0.94 (9). In this study, Cronbach's Alpha internal consistency coefficient of the scale was found as 0.93 .

\section{Data Collection}

The research data was collected from the students who are studying at the related universities and agreed to participate in the research. The data was sent to the students through social media accounts (WhatsApp student groups) with online questionnaires prepared by means of Google Forms and they were asked to fill in. It took each participant 10-15 minutes on average to complete the questionnaires.

\section{Data Assessment}

For statistical analyses of the data obtained, SPSS 25.0 for Windows software (SPSS, Chicago, II, USA) was used. In the statistical assessment, descriptive statistics average, standard deviation, percentage distribution and Pearson Correlation Analysis were used. Significance level was assessed as $p<0.05$.

\section{Ethical Regulations}

For implementation of the research, ethical approval was taken from the Ministry of Health Turkey (202012-24T00_14_08) and Inonu University Health Sciences Scientific Research and Publication Ethics Committee (Decision No: 2021/1447). Before starting the research, institutional permissions were also taken from related universities. At the beginning of questionnaire items, students were informed about the aim of the research and volunteering students were asked to fill in the questionnaires.

\section{RESULTS}

Distribution of descriptive properties of midwifery students is given in Table $1.27 .7 \%$ of midwifery students whose average age is $20.70 \pm 2.09$ are at 1 st year, again $27.7 \%$ of them are at the $2 \mathrm{nd}$ year and $50.4 \%$ of them are studying at University A. $75.8 \%$ of students stated that they have nuclear family, $59.9 \%$ stated that they live in the province, $65.5 \%$ stated that they income is equal to their outcome, $39.5 \%$ stated that their mothers and $30.0 \%$ stated that their fathers 
Table 1. Distribution of Descriptive Properties of Midwifery Students ( $n=484$ )

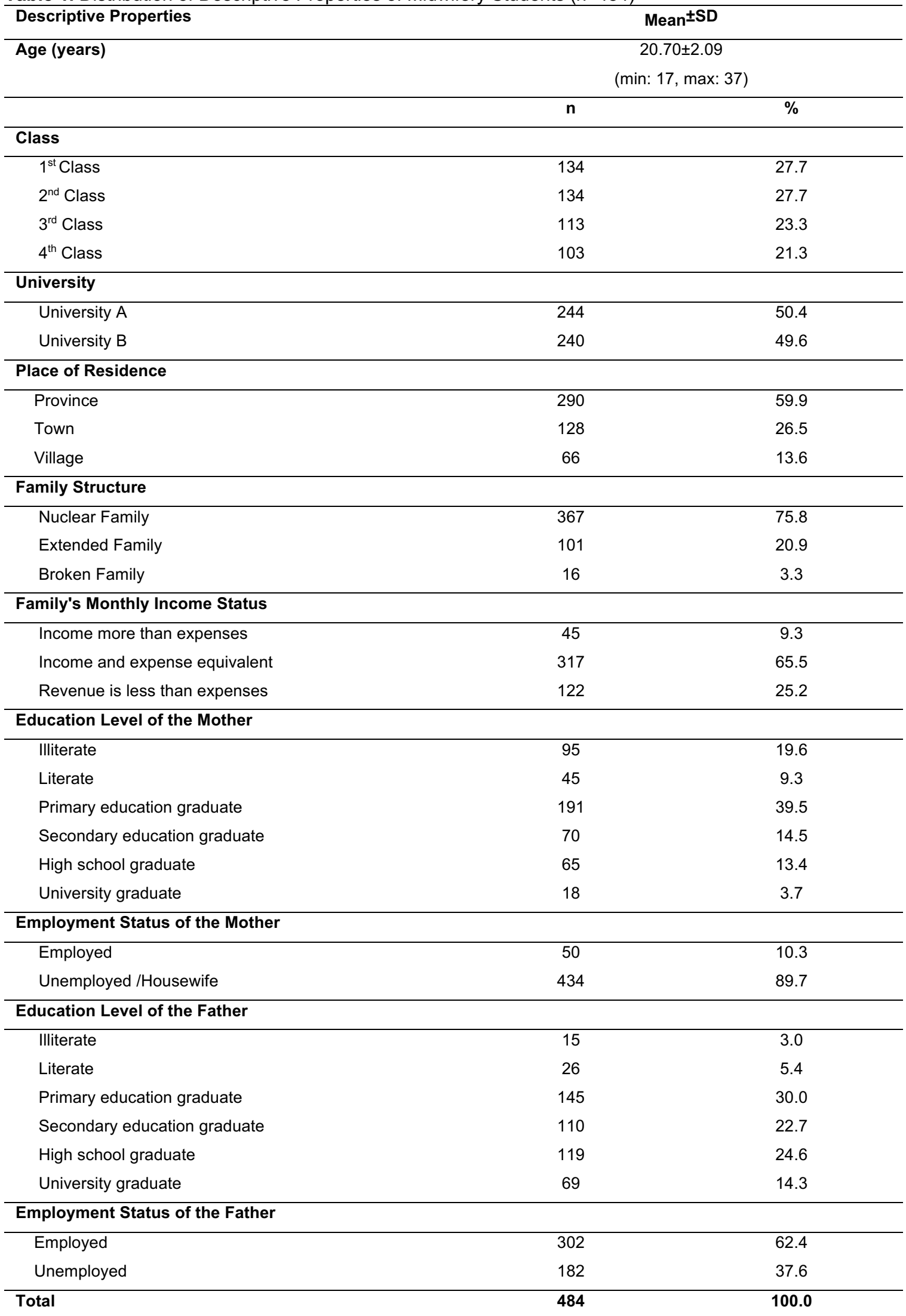

SD: Standard Deviation 
Table 2. Lowest-Highest Scores that can be Obtained from SLS, FSBS and C19P-SE Total and Sub-dimensions and the Distribution of Lowest-Highest Scores and Average Scores that Participants Obtained $(n=484)$

\begin{tabular}{lccccc}
\hline Scales & Mean+SD & $\begin{array}{c}\text { Lowest-Highest Scores } \\
\text { that can be Obtained }\end{array}$ & $\begin{array}{c}\text { Lowest-Highest Scores } \\
\text { that Obtained }\end{array}$ \\
\hline SLS Total & $13.54 \pm 4.37$ & 5 & 25 & 5 & 25 \\
\hline FSBS Total & $64.91 \pm 13.50$ & 17 & 85 & 17 & 85 \\
Sense of Self-belonging & $47.94 \pm 10.65$ & 12 & 60 & 12 & 60 \\
Family Sense of Belonging & $16.97 \pm 3.60$ & 5 & 25 & 5 & 25 \\
\hline C19P-SE Total & $50.02 \pm 17.36$ & 20 & 100 & 20 & 100 \\
Psychological Phobia & $18.25 \pm 6.42$ & 6 & 30 & 6 & 30 \\
Psycho-somatic Phobia & $10.03 \pm 4.47$ & 5 & 25 & 5 & 25 \\
Economic Phobia & $8.28 \pm 3.76$ & 4 & 20 & 4 & 20 \\
Social Phobia & $13.44 \pm 5.34$ & 5 & 25 & 5 & 25 \\
\hline
\end{tabular}

SLS: The Satisfaction with Life Scale

FSBS: Family Sense of Belonging Scale

CP19-SE: Coronavirus 19 Phobia Scale

SD: Standard Deviation

are primary school graduates. While the rate of students who stated that their mothers are working at a job is $10.3 \%$, the rate of students who stated that their fathers are working at a job is $62.4 \%$.

Lowest-highest scores that can be obtained from SLS, FSBS and C19P-SE total and sub-dimensions and the distribution of lowest-highest scores and average scores that participants obtained are given in Table 2. The lowest and highest score that midwifery students obtained from SLS was found as 5-25 and their average score was found as $13.54 \pm 4.37$.

The lowest and highest score that midwifery students obtained from FSBS was found as 17-85 and their average score was found as $64.59 \pm 13.29$. The lowest and highest score that midwifery students obtained from FSBS Sense of Self-Belonging sub-dimension was found as 12-60 and their average score was found as 47.94 \pm 10.65 ; the lowest and highest score that midwifery students obtained from FSBS Family Sense of Belonging sub-dimension was found as 525 and their average score was found as $16.97 \pm 3.60$. The lowest and highest score that midwifery students obtained from C19P-SE was found as 20-100 and their average score was found as $50.02 \pm 17.36$. The lowest and highest score that midwifery students obtained from C19P-SE Psychological Phobia subdimension was found as 6-30 and their average score was found as $18.25 \pm 6.42$; the lowest and highest score that midwives obtained from Psychosomatic Phobia sub-dimension was found as 5-25 and their average score was found as $10.03 \pm 4.47$; the lowest and highest score that midwifery students obtained from Economic Phobia sub-dimension was found as 4-20 and their average score was found as 8.28 \pm 3.76 ; the lowest and highest score that midwifery students obtained from Social Phobia subdimension was found as 5-25 and their average score was found as $13.44 \pm 5.34$.

The relationship between total and sub-dimension average scores of SLS, FSBS and C19P-SE scales are given in Table 3 . It was determined that FSBS total and all sub-dimension average scores increased significantly as C19P-SE scale "Psychological Phobia" sub-dimension average score increases $(p<0.05)$. In addition, it was also determined that FSBS "Family Sense of Belonging" sub-dimension average score increases significantly as C19P-SE scale "Social Phobia" sub-dimension average score increases $(p<0.05)$. However, it was determined that Satisfaction with Life decreases significantly as the average scores in C19P-SE scale "Psycho-somatic Phobia" and "Economic Phobia" sub-dimension average scores increase $(p<0.05)$. It was seen that FSBS total average score increases significantly as the average score in C19P-SE scale "Social Phobia" sub-dimension increases $(p<0.05)$. It was determined that FSBS Family Sense of Belonging average score increases significantly as the total score of C19P-SE scale increases $(p<0.05)$. 
Table 3. The Relationship between SLS, FSBS and C19P-SE Total and Sub-dimensions $(n=484)$

\begin{tabular}{|c|c|c|c|c|}
\hline Scales & \multicolumn{3}{|c|}{ Family Sense of Belonging Scale (FSBS) } & $\begin{array}{c}\text { The Satisfaction wit } \\
\text { Life Scale (SLS) } \\
\text { SLS Total }\end{array}$ \\
\hline $\begin{array}{l}\text { Coronavirus } 19 \text { Phobia } \\
\text { Scale (C19P-SE) }\end{array}$ & $\begin{array}{c}\text { FSBS-Family } \\
\text { Sense of } \\
\text { Belonging }\end{array}$ & $\begin{array}{l}\text { FSBS-Sense of } \\
\text { Self Belonging }\end{array}$ & FSBS Total & SLS Total \\
\hline C19P-SE Psychological & $r=0.176$ & $r=0.107$ & $r=0.131$ & $r=0.062$ \\
\hline Phobia & ${ }^{*} p=0.000$ & ${ }^{*} p=0.018$ & ${ }^{*} p=0.004$ & $p=0.175$ \\
\hline C19P-SE Psycho-somatic & $r=0.041$ & $r=0.001$ & $r=0.012$ & $r=-0.113$ \\
\hline Phobia & $p=0.366$ & $p=0.977$ & $p=0.792$ & ${ }^{*} p=0.013$ \\
\hline \multirow[t]{2}{*}{ C19P-SE Economic Phobia } & $r=0.018$ & $r=-0.034$ & $r=-0.022$ & $r=-0.108$ \\
\hline & $p=0.687$ & $p=0.457$ & $p=0.632$ & ${ }^{*} p=0.017$ \\
\hline \multirow[t]{2}{*}{ C19P-SE Social Phobia } & $r=0.146$ & $r=0.071$ & $r=0.095$ & $r=-0.009$ \\
\hline & ${ }^{*} p=0.001$ & $p=0.119$ & ${ }^{*} p=0.037$ & $p=0.851$ \\
\hline \multirow[t]{2}{*}{ C19P-SE Total } & $r=0.125$ & $r=0.054$ & $r=0.076$ & $r=-0.032$ \\
\hline & ${ }^{*} p=0.006$ & $p=0.232$ & $p=0.094$ & $p=0.477$ \\
\hline
\end{tabular}

$r=$ Pearson Correlation Analyze $\quad p<0.05$

SLS: The Satisfaction with Life Scale

FSBS: Family Sense of Belonging Scale

CP19-SE: Coronavirus 19 Phobia Scale

\section{DISCUSSION}

COVID-19 phobia affects all parts of the society negatively. However, it was also reported that people who might be subjected to negative outcomes more during the pandemic are the old, young, women and students $(1,14)$. Starting to spend more time with their families together with the lockdown which is one of the measures taken because of the pandemic, the students have given up their daily routines and they have been physically depressed. As a result of this, students face psychological problems. In addition, their satisfaction with life and family sense of belonging levels would be affected negatively. In this section, the results of the study conducted with the purpose of determining the impact of Covid-19 phobia on the satisfaction with life and family sense of belonging levels of midwifery students are discussed with the related literature.

The total average score that midwifery students obtained from C19P-SE was found as $50.02 \pm 17.36$.
In addition, the average scores that students obtained from Psychological Phobia, Psychosomatic Phobia, Economic Phobia and Social Phobia sub-dimensions are determined as $8.25 \pm 6.42,10.03 \pm 4.47,8.28 \pm 3.76$, $13.44 \pm 5.34$ respectively (Table 2 ). In literature review, no study was found on COVID-19 phobia in students. In a study investigating COVID-19 phobia in healthcare professionals, it was determined that healthcare professionals' phobia is high (15). In addition, it was also determined that women experience higher coronavirus phobia than men (16, $17)$. In addition to these results, it was also reported that individuals are afraid of getting coronavirus (16, 18, 19). During COVID-19 pandemic, it was reported that people's routines were disturbed and for that reason anxiety and phobic reactions occurred $(2,6$, $20,21)$. Furthermore, it is also emphasized that people are afraid of being infected with COVID-19 and they may experience negative emotional states such as phobia, anxiety, depression and despair in 
the short and long term with the impact of natural disasters such as earthquake or tsunami, man-made disasters such as explosions, wars or terrorism or epidemics such as MERS, SARS or Ebola (2, 22-24). When considered from this point of view, COVID-19 phobia level obtained from midwifery students (Table 2) can be assessed in parallel to other age groups and interpreted as a potential result.

The average score that midwifery students obtained from Satisfaction with Life Scale was found as $13.54 \pm 4.37$ (Table 2). Considering that maximum score that can be obtained from the scale is 25 , it can be said that satisfaction with life of the students participated in the study is on moderate level. In literature review, many studies have been found investigating the satisfaction with life in female university students. However, those studies indicate that students' satisfaction with life is high unlike our results (25-30). It is thought that this difference in literature is caused by the pandemic process. In fact, in Yavas Celik's (2020) study investigating satisfaction with life in university students in COVID19 process, it was determined that students' satisfaction with life is on moderate level similar to our result (31).

The average score that midwifery students obtained from Family Sense of Belonging Scale was found as $64.59 \pm 13.29$ (Table 2). When the total score obtained from the scale is examined, it can be said that students have high family sense of belonging. No study has been found investigating the university students' family sense of belonging during the COVID-19 process. However, social isolation and lockdown rules have become important with the pandemic and as all other individuals, students also started to spend more time with their families. As an ordinary advantage of this process, midwifery students' family sense of belonging may have increased.

It was determined that the average score students obtained from FSBS Family Sense of Belonging Subdimension increase significantly as the total score that students obtained from C19P-SE scale increases $(p<0.05)$ (Table 3). As it is understood from study results, it is determined that there is a significant relationship between the average scores obtained from Coronavirus 19 Phobia (C19P-SE) Scale total and sub-dimensions and average scores obtained from Family Sense of Belonging Scale total and subdimensions and that midwifery students' family sense of belonging levels increase as their level of COVID-
19 Phobia increases. In literature review, no study has been found on COVID-19 Phobia and family sense of belonging level in students. When assessed from this point of view, our result is an important result for the literature. With quick spread of coronavirus, a crisis has occurred and social isolation and lockdown rules were implemented and individuals stayed at home. As all other individuals, students also fit their lives in their homes and maybe university students who left their families for their education started to spend more time with their families with distance education. When the historical process is examined, it is seen that all kinds of crises, especially epidemics affect the individual and his surroundings, therefore his family structure in different aspects $(10-12,32$, 33). Family, which constitutes the foundation of society, is a structure that enables emotions in daily life such as love, attachment, happiness and belonging and situations such as listening to each other, spending time together, sparing some time for each other, supporting and being happy and sad together (30). With the impact of pandemic process, it was reported that social and even psychological isolation was formed with people staying at home and this situation resulted in alienation, withdrawal and therefore discussion among people. In addition to those, it is also stated that voices are raised in communication, domestic discussions occurred and incidents occurred leading up to domestic violence and all those incidents are extensions of the crisis within the family (34). Furthermore, it was also reported that domestic relationships may also be affected positively in the lockdown process (10).

It was determined that satisfaction with life decreased significantly as their average score from CP19-SE scale "Psychosomatic Phobia" and "Economic Phobia" sub-dimensions' increase $(p<0.05)$ (Table 3$)$. In literature review, it was determined that COVID-19 phobia affect individuals' satisfaction with life negatively similar to our result $(4,35-37)$. The stress and fear that individuals experience in pandemic process affect their state of health. The most important factor for enjoying the life and leading a happy life is being healthy. Because, even if individuals have many financial means, they cannot do what they want and they cannot be satisfied with their lives unless they are healthy. In literature review, it was determined that satisfaction with life of university students who have no disease is higher (26). Other studies indicate that satisfaction with life levels of individuals with chronic diseases are lower 
than individuals who have no disease (27). In addition, in his study, Chow (2005) emphasized that physical health has a significant place among the determinants of satisfaction with life (38). There are also study results indicating that mental diseases affect satisfaction with life negatively as well as physical and biological diseases (13, 26, 39). In the study investigating the relationship between satisfaction with life and death anxiety; it was determined that there is a correlation between individuals' satisfaction with life and death anxiety and satisfaction with life decreases as death anxiety increases (40). The fear of disease, getting infected and dying that individual have during COVID-19 pandemic and the negative conditions they are involved in affect satisfaction with life by causing both physiological and psychological stress (4).

\section{Limitations}

Research is limited to midwifery students studying at the two universities in the east of Turkey.

\section{CONCLUSION}

As a result of the research, it was determined that midwifery students have a moderate level of COVID19 phobia and their psychological and social phobia levels regarding COVID-19 increased their family sense of belonging, but psychosomatic and economic phobia levels decreased their satisfaction with life. The threat perception that occurred together with the pandemic causes fear and stress among individuals and make the individuals more sensitive than ever. For that reason, managing the uncertainty and the crisis that occur in during pandemics, investigating its emotional and psychosocial impacts carefully and implementing the coping methods effectively have a significant place for individuals and the society. It is important that the phobia, which occurs with the impact of the pandemic, is diagnosed early among the students who are among the group most affected by the pandemic and psychological support is provided in time.

Acknowledgements: We would like to thank the midwifery students who participated and completed this questionnaire.

Conflict of interests: The authors have no conflicts of interest to disclose.

Funding: The financial support for this study was provided by the investigators themselves.

Ethics Consideration: For implementation of the research, ethical approval was taken from the Ministry of Health Turkey (2020-12 24T00_14_08) and Malatya Inonu University Health Sciences Scientific Research and Publication Ethics Committee (Decision
No: 2021/1447). Before starting the research, institutional permissions were also taken from related universities. At the beginning of questionnaire items, students were informed about the aim of the research and volunteering students were asked to fill in the questionnaires.

Author contribution: Study design: SA, ANY, YAD. Data collection: SA, ANY. Data analysis: SA, ANY, YAD. Study supervision: YAD. Manuscript writing: SA, ANY, YAD. Critical revisions for important intellectual content: SA, ANY, YAD.

Peer-review: Externally peer-reviewed.

\section{REFERENCES}

1. Grubic N, Badovinac S, Johri AM. Student mental health in the midst of the COVID-19 pandemic: A call for further research and immediate solutions. International Journal of Social Psychiatry 2020; 66(5): 517-518.

2. Arpaci I, Karatas K, Baloglu M. The development and initial tests for the psychometric properties of the COVID-19 Phobia Scale (C19P-S). Pers Individ Dif 2020; 164: 110108.

3. Aksoy Derya $Y$, Altiparmak S, Akca E, et. al. Pregnancy and birth planning during COVID-19: The effects of tele-education offered to pregnant women on prenatal distress and pregnancyrelated anxiety. Midwifery 2021; 92: 102877.

4. Satici B, Gocet-Tekin E, Deniz ME, et. al. Adaptation of the Fear of COVID19 Scale: Its association with psychological distress and life satisfaction in Turkey. International Journal of Mental Health and Addiction 2020; 1-9.

5. Kim CW, Song HR. Structural relationships among public's risk characteristics, trust, risk perception and preventive behavioral intention: The case of MERS in Korea. Crisisnomy 2017; 13: 85-95.

6. Li S, Wang Y, Xue J, et al. The impact of COVID19 epidemic declaration on psychological consequences: a study on active Weibo users. Int J Environ Res Public Health 2020; 17(6): 2032.

7. Daglı A, Baysal N. Adaptation of The Satisfaction with Life Scale into Turkish: The study of validity and reliability. Electronic Journal of Social Sciences 2016; 15(59): 1250-1263.

8. Calıskan M, Toker M, Ozbay Y. Validity and Reliability Analysis of Family Life Satisfaction Scale. International Journal Of Early Childhood Educaiton Studies 2017; 2: 1-9.

9. Mavili P, Kesen O, Dasbas O. Family Sense of Belonging Scale: A Study of Developing a Scale. Journal of Social Policy Studies 2014; 33: 29-45. 
10. Isik A. Crisis Intervention in Family During Coronavirus (Covid-19) Pandemic. Academia Journal of Nature and Human Sciences 2020; 6(1): 1-9.

11. Kluwer E. Families in time of Corona. 2020. (Date of Access: 02.03.2021). https://nias.knaw.nl/food-for-thought/families-intimes-of-corona/

12. Ozturk MS, Yılmaz N, Demir Erbil D, et. al. Examination of Conflict and Cohesion Situation in Household During Covid-19 Pandemic Period. Turkish Studies 2020; 15(4): 295-314.

13. Diener E, Seligman MEP. Beyond money: Toward an economy of well-being. Psychoogical Science in the Public Interes 2004; 5(1), 31.

14. Tian F, Li H, Tian S, et al. Psychological Symptoms of Ordinary Chinese Citizens Based on SCL-90 During the Level I Emergency Response to COVID-19. Psychiatry Research 2020; 288: 112992.

15. Amin S. (2020) The psychology of coronavirus fear: Are healthcare professionals suffering from corona-phobia? International Journal of Healthcare Management 13; 3: 249-256,

16. Ahorsu DK, Lin CY, Imani V, et al. The fear of COVID-19 scale: development and initial validation. International journal of mental health and addiction 2020; 1-9.

17. Arpaci İ, Karatas K, Baloglu M, et al. COVID-19 Phobia in the United States: Validation of the COVID-19 Phobia Scale (C19PSE). Death Studies 2021; 1-7.

18. Andrade EF, Pereira LJ, de Oliveira APL, et al. Perceived fear of COVID-19 infection according to sex, age and occupational risk using the Brazilian version of the Fear of COVID-19 Scale. Death Studies 2020; 1-10.

19. Haktanir A, Seki T, Dilmac B. Adaptation and evaluation of Turkish version of the fear of COVID-19 Scale, Death Studies 2020; 1-9.

20. Duan L, Zhu G. Psychological interventions for people affected by the COVID-19 epidemic. Lancet Psychiatry 2020; 7(4): 300-302.

21. Wang G, Zhang $Y$, Zhao J, et al. Mitigate the effects of home confinement on children during the COVID-19 outbreak. The Lancet 2020; 395(10228): 945-947.

22. Hossain MM, Sultana A, Purohit N. Mental health outcomes of quarantine and isolation for infection prevention: A systematic umbrella review of the global evidence. SSRN Electronic Journal 2020; 42: 1-11.

23. Qi J, Yang X, Tan R, et al. Prevalence and predictors of posttraumatic stress disorder and depression among adolescents over 1 year after the Jiuzhaigou earthquake. Journal of Affective Disorders 2020; 261: 1-8.

24. Steinberg JW, Daniel J. Depression as a major mental health problem for the behavioral health care industry. Journal of Health Sciences Management and Public Health 2020; 1: 44-49.

25. Gulcan A, Nedim Bal P. Examining the effect of optimism on happiness and life satisfaction in young adults. E-AJI (Asian Journal of Instruction) 2014; 2(1): 41-52.

26. Yumusak, M. The levels of smart phone addiction, sleep quality and satısfaction with life in university students. Master Thesis, Erciyes University, 2019.

27. Ozgur G, Babacan Gumus A, Durdu B. Life Satisfaction of university students living at home or in the dormitory. Journal of Psychiatric Nurses 2010; 1(1): 25-32.

28. Sahin A. Relationships between conscious awareness and life satisfaction and well-being in university students. Uskudar University Journal of Social Sciences 2019; (8): 151-176.

29. Ozkaya G. Relationship between loneliness levels and hopelessness and life stisfaction of university students. Doctoral dissertation, Halic University, 2017.

30. Kokcu H. Relationship between family religious activities, religious attitudes and life satisfaction among university students. Master's thesis, Istanbul Sabahattin Zaim University, 2019.

31. Yavas Celik M. The effect of staying at home due to COVID-19 outbreak on nursing students' life satisfaction and social competencies. Perspectives in Psychiatric Care 2020; 1-5.

32. Prime $H$, Wade $M$, Browne DT. Risk and resilience in family well-being during the COVID19 pandemic. American Psychologist 2020; 75(5), 631-643.

33. Su L, Ma X, Yu H, et al. The different clinical characteristics of corona virus disease cases between children and their families in China-the character of children with COVID-19. Emerging microbes \& infections 2020; 9(1):707-713.

34. Usher K, Bhullar N, Durkin J, et al. Family violence and COVID-19: Increased vulnerability and reduced options for support. International 
Journal of Mental Health Nursing (2020) 29, 549552.

35. Blasco-Belled A, Tejada-Gallardo C, TorrellesNadal C, et al. The costs of the COVID-19 on subjective well-being: An analysis of the outbreak in Spain. Sustainability 2020; 12: 6243.

36. Zacher H, Rudolph CW. Individual differences and changes in subjective wellbeing during the early stages of the COVID-19 pandemic. American Psychologist. Advance online publication. 2020; 76(1): 50-62.

37. Satıcı B, Sarıcalı M, Satıcı SA, et al. Intolerance of uncertainty and mental wellbeing: Serial mediation by rumination and fear of COVID-19. International Journal of Mental Health and Addiction 2020, page 1-12.

38. Chow HPH. Life satisfaction among university students in a Canadian prairie city: A multivariate analysis, Social Indicators Research 2005; 70 : 139-150.

39. Ummet D. The mediating role of marital adjustment in the relationship between general psychological health and life satisfaction. Itobiad: Journal of the Human \& Social Science Researches 2017; 6(1): 159-175.

40. Arslan A. Investigation of the relationship between life satisfaction and death anxiety in university students. Journal of Education and Social Research 2019; 6(1): 113-129. 